\title{
A formação de pedagogos indígenas em alternância no Paraná: uma contribuição à interculturalidade e ao bilinguismo
}

\author{
Marcos Gehrke ${ }^{1}$, Marlene Lucia Siebert Sapelli ${ }^{2}$, Rosangela Célia Faustino ${ }^{3}$ \\ 1,2 Universidade Estadual do Centro Oeste - UNICENTRO. Departamento de Pedagogia/Laboratório da Educação do Campo e \\ Indígena. Rua Salvatore Renna - Padre Salvador, 875. Santa Cruz, Guarapuava - PR. Brasil. ${ }^{3}$ Universidade Estadual de \\ Maringá - UEM. \\ Autor para correspondência/Author for correspondence: marcosgehrke@gmail.com.br
}

\begin{abstract}
RESUMO. O objetivo do artigo é apresentar o processo de constituição da experiência de formação de pedagogos indígenas, da Universidade Estadual do Centro Oeste (Guarapuava/PR), destacando a chegada da demanda indígena à Universidade, a construção participativa do Projeto Pedagógico do Curso (PPC) e a implementação da Pedagogia da Alternância na formação superior indígena no Paraná. Por meio de pesquisa documental e bibliográfica, explicita-se o protagonismo dos movimentos indígenas na luta pelo direito de acesso ao Ensino Superior, no Paraná, numa perspectiva intercultural e bilíngue, e a premente necessidade de formação de pedagogos para atuarem nas escolas indígenas no estado. $\mathrm{Na}$ contextualização do processo de criação do curso de Pedagogia Indígena, com a Pedagogia da Alternância, destacam-se os princípios que sustentam ações projetadas e realizadas coletivamente, presentes no Projeto Pedagógico e na execução do Curso. Os resultados do processo formativo em andamento evidenciam uma melhor participação dos povos indígenas nas decisões e na organização da formação superior indígena, a concretização de um currículo intercultural e bilíngue, bem como a constituição de uma Licenciatura Intercultural, composta apenas por estudantes indígenas, que tem protagonizado ações com autonomia e autogestão.
\end{abstract}

Palavras-chave: Pedagogia Indígena, Pedagogia da Alternância, Ensino Superior Indígena, Formação Intercultural e Bilíngue.

\begin{tabular}{|l|l|l|l|l|l|l|} 
RBEC & Tocantinópolis/Brasil & v. 4 & e7350 & $10.20873 /$ uft.rbec.e7350 & 2019 & ISSN: 2525-4863 \\
\hline
\end{tabular}




\title{
The training of indigenous pedagogues in alternance in Paraná: a contribution to interculturality and bilinguism
}

\begin{abstract}
The aim of this paper is to present the constitutional process of the experience of indigenous educators development of the Central West State University (Guarapuava/PR), highlighting the arrival of indigenous demand at the University, the participatory construction of the Pedagogical Project of the Course (PPC) and the implementation of Alternation Pedagogy in indigenous higher education in Paraná. Through documentary and bibliographical research, the role of indigenous movements in the fight for the right of access to higher education in Paraná is explained in an intercultural and bilingual perspective, and the urgent need for training of educators to work at indigenous schools in the state. In the context of the process of creation of the course of Indigenous Pedagogy, with the Pedagogy of Alternation, we highlight the principles that support actions designed and performed collectively, present in the Pedagogical Project and in the execution of the Course. The results of the ongoing development process show a better participation of indigenous peoples in the decisions and organization of indigenous higher education, the establishment of an intercultural and bilingual curriculum, as well as the establishment of an Intercultural Degree in Teaching, composed only of indigenous students, which has led actions with autonomy and self-management.
\end{abstract}

Keywords: Indigenous Pedagogy, Alternation Pedagogy, Indigenous Higher Education, Intercultural and Bilingual Training. 


\section{La formación de pedagogos indígenas en alternancia en Paraná: una contribución a la interculturalidad y al bilingüismo}

RESUMEN. El objetivo de este trabajo es presentar el proceso de constitución de la experiencia de formación de educadores indígenas, de la Universidad Estatal des Centroeste (Guarapuava/PR), destacando la llegada de la demanda indígena a la Universidad, la construcción participativa del Proyecto Pedagógico del Curso (PPC) y la implementación de la Pedagogía de Alternancia en la educación superior indígena en Paraná. A través de la investigación documental y bibliográfica, se explica el papel de los movimientos indígenas en la lucha por el derecho de acceso a la educación superior en Paraná, desde una perspectiva intercultural y bilingüe, y la necesidad urgente de capacitar a educadores para trabajar en escuelas indígenas en el estado. En el proceso de creación del curso de Pedagogía Indígena, con la Pedagogía de Alternancia, destacamos los principios que apoyan las acciones diseñadas y realizadas colectivamente, presentes en el Proyecto Pedagógico y en la ejecución del Curso. Los resultados del proceso de capacitación, en curso, muestran una mejor participación de los pueblos indígenas en las decisiones y la organización de la educación superior indígena con el establecimiento de un plan de estudios intercultural y bilingüe, y la creación de un curso intercultural, compuesto solo por estudiantes indígenas, que ha liderado acciones con autonomía y autogestión.

Palabras clave: Pedagogía Indígena, Pedagogía de Alternancia, Educación Superior Indígena, Entrenamiento Intercultural y Bilingüe. 


\section{Introdução}

Embora a escola esteja presente entre os povos indígenas no Brasil desde cinco séculos, esta, em seu projeto de criação, objetivou cooperar com a integração visando à expropriação dos territórios, a sujeição e disciplinarização da força de trabalho indígena. Servindo aos interesses da colonização, a escola entre os povos indígenas se torna uma das instituições usadas como canal de transmissão de valores da sociedade ocidental mercantilista, e um aparato de controle se estabelece para garantir tal propósito.

Os povos indígenas, historicamente, lutam e resistem à invasão de suas terras e à imposição de epistemologias dominantes. Desenvolveram uma série de estratégias desde o enfrentamento e as guerras, até as negociações com o poder público e, assim, por meio de vertiginosos movimentos organizados que obtiveram mais visibilidade a partir dos anos de 1970, articulados com os demais movimentos sociais (Ramos, 1984), foram influenciando e mudando as políticas públicas e educacionais. Desde a Constituição Federal de 1988, houve significativas alterações nos direitos educacionais indígenas possibilitando a construção de uma educação escolar indígena intercultural e bilíngue.
Os movimentos sociais indígenas pan-americanos (Ramos, 2012) contam com o apoio de universidades, instituições da sociedade civil e indigenistas e, assim, em nível internacional fez constituir-se uma legislação específica e proteção aos direitos indígenas destacando-se o direito à terra, à saúde, à educação e autodeterminação.

A educação pautada no uso das línguas indígenas e conhecimentos étnicos na escola com projetos pedagógicos, currículos e calendários interculturais próprios, passou a exigir maior presença de professores indígenas qualificados, bilíngues e engajados nos movimentos por autonomia, autogestão $\mathrm{e}$ autossustentabilidade indígena.

Educação escolar intercultural e bilíngue significa que a escola, em territórios indígenas, não será colonizadora, baseada na cultura e economia ocidental. Não terá suas regras de funcionamento, seus currículos, seu projeto pedagógico desenhado e imposto por entes do Estado e, sim, que os povos indígenas, exercendo a autonomia, garantida nos aparatos legais e na Convenção 169 da Organização Internacional do Trabalho (OIT), proporão projetos e participarão da tomada de 
decisões nas políticas educacionais, em situação de igualdade.

De acordo com a legislação vigente as comunidades indígenas, conforme suas realidades socioculturais e linguísticas, buscam fazer proposições de seus projetos pedagógicos escolares, contemplando conhecimentos étnicos e processos próprios de ensino e aprendizagem. Conforme a legislação nacional (Lei n. 9394, 1996); (Diretrizes, 2014), estas mudanças necessitam da presença e participação de professores indígenas, qualificados em formação superior, ocupando as funções de pedagogos, gestores e professores bilíngues na Educação Básica Indígena.

Considerando os séculos de colonização e tutela, a formação superior indígena, em universidades públicas, teve início muito recentemente, datando dos anos de 2000 (Novak, 2014). Antes disso, o Estado brasileiro estabelecera convênios com agências religiosas como o Summer Institut of Linguistcs (SIL) para a formação de monitores, desenvolvida sob doutrinamento religioso (Barros, 1993; Faustino, 2006).

Com as políticas públicas conquistadas pelos povos indígenas, em relação à educação básica e superior, firmadas tanto na CF de 1988, como na Lei de Diretrizes e Bases da Educação
(LDBEN 9394/96), desenvolveram-se, no Brasil, basicamente dois modelos de formação para professores indígenas: as Licenciaturas Interculturais e o acesso diferenciado por meio de cotas ou outras ações afirmativas nos diferentes estados brasileiros.

No Paraná, as lideranças indígenas negociaram o direito de acesso à formação superior com o estado e este, por meio da Lei Estadual 13.134 de 2001, instituiu, nas sete universidades públicas, a criação de três vagas suplementares anuais, nos diferentes cursos superiores, para o ingresso de indígenas territorializados no Paraná, com financiamento da Secretaria de Estado da Ciência, Tecnologia e Ensino Superior (SETI). Posteriormente, no ano de 2006, a Lei 14.995 duplicou o número de vagas a serem ofertadas pelas IES públicas. O financiamento estadual cobre tanto a realização de vestibulares específicos (Rodrigues; Wawzyniak, 2005; Novak, 2007; 2014), como bolsas auxílio, mensais, que os estudantes indígenas, matriculados e frequentando, assiduamente, os cursos superiores das IES públicas, têm direito.

Assim, desde 2002 vem sendo realizados Vestibulares dos Povos Indígenas (Novak, 2007; 2014), para ocupação das vagas suplementares que, totalizadas, somam cerca de 650 (seiscentos e cinquenta), ofertadas pelas 
Universidades Estaduais, e mais cerca de 150 (cento e cinquenta) vagas ofertadas na Universidade Federal do Paraná (que recebe indígenas do Paraná e também de outros estados brasileiros).

Das 650 vagas ofertadas e ocupadas por estudantes indígenas nas IES estaduais, até o ano de 2018, conforme dados organizados por (Faustino; Novak e Cipriano, 2013) e atualizados com informações anuais da Comissão Universidade para os Índios (CUIA), apenas 65 indígenas concluíram seus cursos.

Os indígenas que ingressam no Ensino Superior (ES) no Paraná, via esta política de vagas suplementares, e não se formaram, os motivos são as dificuldades de permanência nas cidades, que são distantes das Terras Indígenas, exigindo a mudança de domicílio, que implica em despesa com valores altos de aluguel e distanciamento da família extensa e da comunidade; ou uso de transporte coletivo, que chega a tomar quatro horas diárias dos estudantes, representando dificuldade de deslocamento diário, principalmente em períodos de chuva.

Outros motivos para a não formação de cerca de $90 \%$ dos estudantes indígenas que efetivam a matrícula no Ensino Superior, nas IES do Paraná, são os altos índices de desistência, repetência e reprovação, causados pelas questões acima apontadas, somadas a situações de preconceito vivenciadas, a questão linguística que interfere na aprendizagem de alguns estudantes que não tem a Língua Portuguesa como L1, dificuldade com conteúdos predominantemente ocidentais, e pelo fato das universidades não ofertarem currículos interculturais e bilíngues nos cursos superiores.

Os índices de conclusão dos cursos estão a exigir mudanças e inovações. $\mathrm{O}$ vagaroso processo de formação superior impacta negativamente na consolidação das escolas interculturais bilíngues na educação básica indígena, uma vez que a maioria dos professores que atua nas escolas indígenas no Paraná não são índios.

No cenário que demandou o Curso de Pedagogia Indígena da UNICENTRO, situa-se a falta de pedagogos/as para atuar na gestão, educação infantil e anos iniciais do Ensino Fundamental, nas 39 (trinta e nove) escolas indígenas do Paraná. Conforme dados da Consulta Escola - Dia a Dia Educação (Consulta Escola, 2018), são cerca de 5.000 (cinco mil) estudantes indígenas matriculados na educação básica. Nestas escolas, apenas 15 (quinze) pedagogos são indígenas que ocupam espaço na gestão e, cerca de 50 (cinquenta) não são índios. Do universo de cerca de 800 (oitocentos) professores atuando, 
apenas 310 (trezentos e dez) são indígenas, ou seja, mais de $60 \%$ dos professores das escolas indígenas no Paraná não são índios e isso tem relação direta com a política de formação superior organizada no estado.

O Vestibular dos Povos Indígenas realizado anualmente pelas IES sob responsabilidade da Comissão Universidade para os Índios (CUIA), colabora no direito ao acesso, mas não viabiliza ou garante a conclusão, ainda que estudantes tenham bolsas auxílio para a permanência. Estudantes indígenas, ao ingressarem no Ensino Superior, ficam dispersos nos cursos/turmas e suas histórias, culturas e identidades não são consideradas nos referidos projetos pedagógicos. Nenhuma universidade estadual no Paraná realizou um curso superior intercultural e bilíngue que contemple as demandas formativas e linguísticas dos povos indígenas do estado.

Desta forma, lideranças indígenas têm buscado alternativas junto às universidades demandando uma formação específica e diferenciada, em nível superior, para suas comunidades. Por meio de pesquisa bibliográfica e documental, neste artigo apresentamos a criação do curso de Pedagogia Indígena na UNICENTRO/PR, organizado a partir da Pedagogia da Alternância, indicando os princípios que sustentam ações realizadas e projetadas para o processo de formação de pedagogos, no contexto do direito de acesso, permanência e formação no Ensino Superior no Paraná. São explicitados e debatidos alguns resultados já alcançados.

\section{Pedagogia Indígena na Unicentro: da demanda dos povos à oferta do Curso}

A criação do curso de Pedagogia Indígena na Universidade Estadual do Centro Oeste - UNICENTRO, em Guarapuava/PR, em regime de alternância, é forjada na conjuntura econômica, política, social e educacional vivida pela classe trabalhadora na atualidade e no contexto específico das lutas dos povos indígenas pelos direitos humanos, entre eles a educação superior pública.

Como a conjuntura é produzida nas contradições, destacamos que no cenário do baixo resultado na conclusão dos cursos, produzido pela forma como tem sido conduzida a política de acesso e permanência de indígenas no Ensino Superior do Paraná, se colocam aspectos de resistência. O trabalho de extensão desenvolvido pelo Laboratório de Educação do Campo e Indígena (LAECI) da UNICENTRO, nas escolas da Terra Indígena Rio das Cobras, iniciado em 2017 ; a juventude indígena com desejo de acessar o ensino superior, a apresentação da demanda do curso, elaborada pela 
comunidade indígena à Universidade, foram fatos que trouxeram para $o$ Vestibular Específico para ingresso no referido curso, 297 inscritos para as 60 vagas. Isto porque não foi estendido, ainda, pela Secretaria de Estado de Ciência e Tecnologia (SETI), para a turma em questão, as mesmas condições, garantidas pelo financiamento aos demais vestibulares específicos dos povos indígenas no Paraná.

As lideranças e comunidades indígenas desejam organizar com autonomia, a escola intercultural e pautaram o curso superior na própria Terra Indígena para que a formação seja específica e diferenciada e que possam acompanhar e contribuir em todas as etapas do processo, desde a elaboração do Projeto Pedagógico do Curso (PPC), até sua execução. A UNICENTRO realizou um vestibular descentralizado com baixíssimo custo, potencializando, assim, o acesso de indígenas ao ensino superior. Professores das universidades públicas do Paraná têm realizado projetos de extensão e ações que contribuem na formação continuada, destacamos os Saberes Indígenas na Escola e o Escola da Terra ${ }^{\text {ii }}$.

Nesse sentido, a partir da demanda de formação superior diferenciada, formalizada pela juventude e lideranças da Terra Indígena Rio das Cobras, desde a carta-pedido (Carta- Pedido de Cursos,
2018) à Reitoria da UNICENTRO é que produzimos o PPC do Curso de Pedagogia em alternância com protagonismo indígena e em parceria com as demais IES do Paraná.

Tratados os elementos de origem, passamos a abordar sobre o movimento de formulação do Projeto Pedagógico do Curso de Licenciatura em Pedagogia para indígenas (UNICENTRO, 2018). Este contou com a participação de muitas mãos e mentes, lideranças, estudantes e educadores indígenas, pesquisadores engajados com a luta indígena. Inicialmente, foi criada uma comissão interna na IES que liderou os trabalhos e passou a reunir documentos, agregar lideranças indígenas, estudantes indígenas já presentes na IES, pesquisadores da educação escolar e superior indígena do Paraná e integrantes da CUIA. Na sequência, realizamos um grande Seminário ${ }^{\mathrm{iii}}$ para conhecer experiências, reunir a comunidade interessada e discutir o PPC. Naquele momento, a comissão foi ampliada e grupos de trabalho foram constituídos para realizar pesquisas e formular as proposições. Cada um dos grupos envolveu os diferentes sujeitos para favorecer o diálogo (Freire, 1987) e engajamento de todos na formulação.

O curso de Licenciatura em Pedagogia, específico para indígenas no 
Paraná, assumiu o caráter de projeto especial, está vinculado ao Departamento de Pedagogia (DEPED/G) da UNICENTRO, é coordenado pelo Laeci, conta com o trabalho e a participação de professores dos diversos cursos do Setor de Ciências Humanas, Letras e Artes (SEHLA), e também por professores pesquisadores das demais IES do Paraná, desde o programa de mobilidade docente (UNICENTRO, 2018).

A UNICENTRO solicitou formalmente, por meio de ofício (UNICENTRO, 2018), ao Conselho Estadual de Educação (CEE) a autorização para oferta do curso fora da IES, na própria Terra Indígena, conforme a demanda indígena. O CEE concedeu a autorização por meio do Parecer CEE/CP n ${ }^{\circ}$ 03/18 de 19 de outubro de 2018, para três ofertas, a partir de 2019, e para o funcionamento do curso no Colégio Estadual Indígena Rio das Cobras, município de Nova Laranjeiras/PR.

Os objetivos formativos previstos no PPC indicam que o curso se destina à formação de professores e pedagogos indígenas para exercer funções da docência e de gestão educacional na Educação Básica e em contextos de educação e saberes indígenas, nos quais sejam previstos processos educativos que requeiram conhecimentos pedagógicos
(UNICENTRO, 2018a, p. 14), destaca o projeto também seus objetivos ${ }^{\text {iv }}$ específicos. Esses são materializados em verbos formativos, ação formadora, assumidos no curso para proporcionar, contribuir, dar, possibilitar, capacitar, instrumentalizar, preparar, habilitar, formar, compreender, desenvolver, exercitar, construir o pedagogo unitário na perspectiva intercultural e bilíngue.

Na definição do PPC fez-se a opção pelas 3200 horas como carga horária, distribuídas em quatro anos letivos, com aulas presencias a partir da Pedagogia da Alternância (Teixeira, Bernartt \& Trindade, 2008), ou seja, com tempos de estudo e trabalho na universidade (TU) e tempos de estudo e intervenção nas comunidades de origem, chamado de tempo comunidade (TC). Na organização pedagógica, cada ano letivo é composto por três ou quatro etapas de até 40 dias letivos no tempo universidade (TU), concentrados no Colégio Estadual Indígena Rio das Cobras, município de Nova Laranjeiras, espaço em que são ministradas as disciplinas e os demais espaços-tempos educativos. O TC se dá entre uma etapa presencial e outra, quando os estudantes são orientados e acompanhados no desenvolvimento de atividades de pesquisa, estágios, intervenções nas escolas e comunidades indígenas, 
produções escritas, efetivando na relação entre os dois tempos o princípio da práxis (Sanches Vásquez, 1968).

A dinâmica formativa do curso prevê, também, a possibilidade de itinerância pelo estado, ou seja, o curso pode desenvolver etapas nas diferentes Terras Indígenas do Paraná e nas universidades parceiras, garantindo assim um conhecimento e intervenção mais profundos nas diferentes realidades socioculturais indígenas.

Destacamos que as categorias do marco teórico do projeto privilegiam as especificidades da educação indígena e da educação escolar indígena na formação dos pedagogos e pedagogas. Estas se materializam no currículo ou na matriz formativa em forma de disciplinas que triangulam a formação humana, a educação e a formação profissional do pedagogo/pedagoga indígena. São categorias que transversalizam a formação: a interculturalidade (Betancourt, 1984); antropologia indígena (Junqueira, 2002); diversidade; a formação multilíngue em Línguas Xetá, Guarani, Kaigang,
Portuguesa e Libras (Guimaraes, 2005); território (Almeida, 2004); educação indígena e educação escolar indígena (Faustino, 2006; Bergamaschi, 2019).

Em consonância com as Diretrizes Nacionais do Curso de Pedagogia, Resolução CNE/CP $n^{\circ}$ 1, de 15 de maio 2006, e as Diretrizes Curriculares Nacionais para a Formação de Professores Indígenas em cursos de Educação Superior, Resolução CNE/CP n ${ }^{\circ} 1$, de 7 de janeiro de 2015, destacamos que o PPC prevê um conjunto de disciplinas na matriz curricular que articulam os conhecimentos da formação geral de professores, outro grupo que trata da especificidade da formação de professores indígenas e um grupo de disciplinas que fundamentam e instrumentalizam a práxis da formação do pedagogo. Por fim, abre-se espaço para disciplinas optativas, ofertadas a partir do terceiro ano do curso, consideradas importantes na formação quando atendem questões específicas e são objeto de investigação dos professores envolvidos no curso.

Quadro 1: Matriz Curricular do Curso de Pedagogia Indígena, Unicentro, 2018.

\begin{tabular}{|c|c|c|}
\hline Série & Disciplinas & Total \\
\hline \multirow{4}{*}{$1^{\mathrm{a}}$} & Agroecologia nos saberes indígenas I & 34 \\
\hline & Língua Portuguesa & 34 \\
\hline & Língua Materna I (Guarani, Kaingang e Xetá) & 68 \\
\hline & Laboratório de Alfabetização e Letramento Bilíngue I & 68 \\
\hline
\end{tabular}




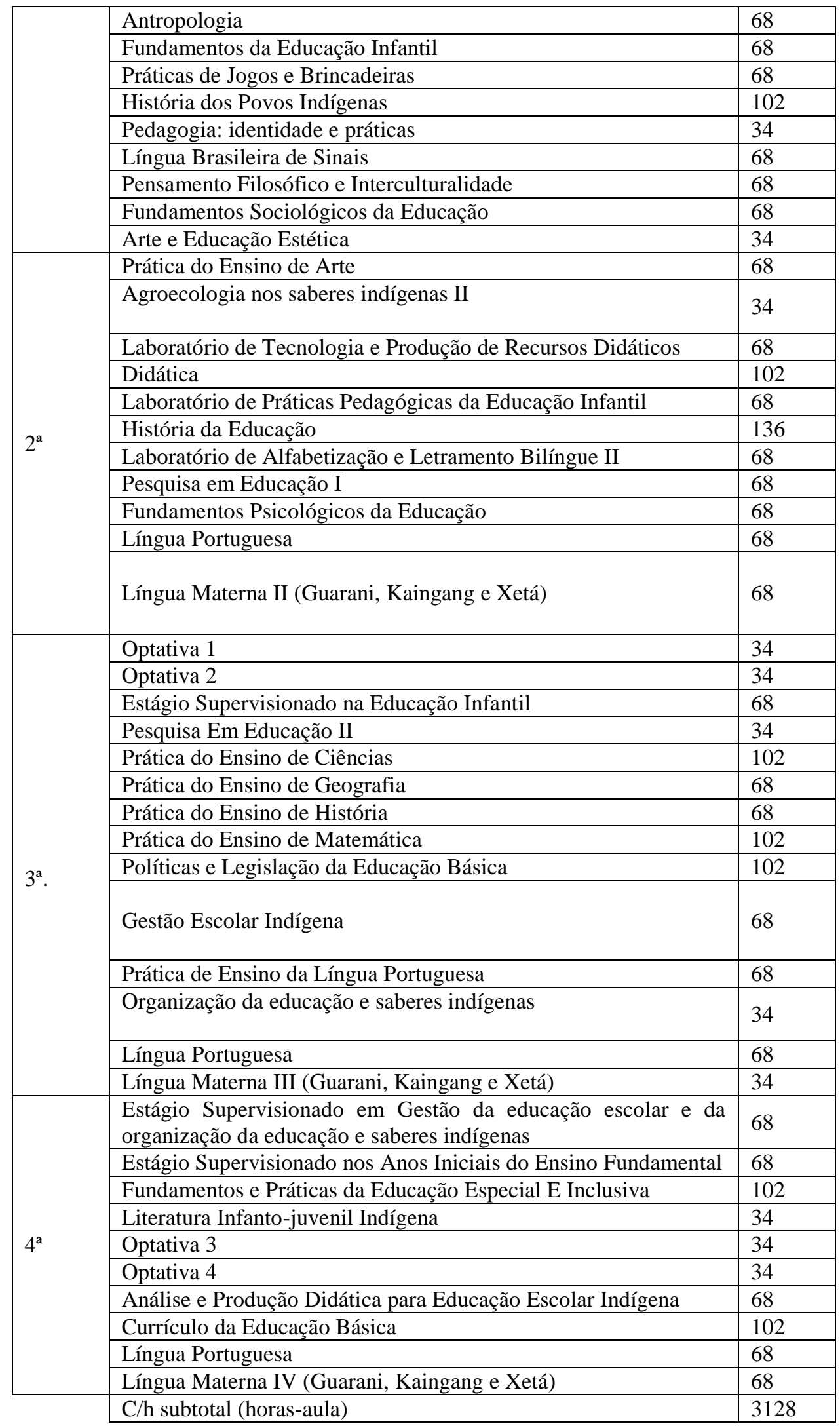

Fonte: UNICENTRO, 2018.

Estabelecida essa breve apresentação geral do curso, passamos a tratar da especificidade da alternância na formação.

Esta, compreendida como estratégia 
político-pedagógica de garantia do direito dos povos indígenas ao ingresso, permanência e à formação com qualidade social/cultural no Ensino Superior público e considerada a participação indígena em todas as etapas do processo, desde a formulação do projeto até seu desenvolvimento e implantação, com acompanhamento, diálogos e avaliação permanente das lideranças indígenas envolvidas, juntamente com a coordenação do Curso, os professores e os estudantes indígenas - futuros pedagogos.

Portanto, os princípios da alternância, nessa experiência, vêm da histórica práxis da Pedagogia da Alternância; das experiências formativas do Movimento dos Trabalhadores Rurais Sem Terra (MST) e, fundamentalmente, de pedagogias indígenas que ainda carecem de reconhecimento e espaço junto às teorias educacionais decoloniais.

A partir dessas referências, no processo de formulação do Curso de Pedagogia Indígena da UNICENTRO/PR, definimos cinco princípios para construir a Pedagogia da Alternância, que apresentamos na sequência e que deram/dão sustentação às várias ações propostas, projetadas e em execução.

a) Alternância como garantia do direito ao ES no lugar onde vivem, trabalham e resistem
Uma das questões fundamentais para se estabelecer uma ação de formação de pedagogos no Ensino Superior, por meio da Pedagogia da Alternância, é atender à garantia legal de acesso e permanência dos estudantes indígenas, pois, em regimes comuns, de frequência diária, as dificuldades são muito maiores, já que envolvem a saída desses sujeitos de suas comunidades por quatro anos ou mais; a fixação de moradia nas cidades, o que envolve custos de aluguel, de alimentação, de transporte, dentre outros; o enfrentamento dos preconceitos; a solidão, perdas de laços societários e políticos com as aldeias de origem e outras questões que acabam promovendo um alto índice de evasão. Para superar essas dificuldades, propusemos, junto com os povos indígenas, a reorganização do trabalho pedagógico na Universidade.

Outra questão a se considerar é que os estudantes indígenas têm o direito de acessar também o ensino presencial, proporcionado pelos Tempo Universidade e Tempo Comunidade, sem comprometer vínculos societários, o que aprofunda a relação teoria-prática e potencializa o contato com a diversidade étnico-cultural indígena, a vivência de práticas de autoorganização, o intercâmbio com outras comunidades, o atendimento imediato às dificuldades de aprendizagem, o acesso a 
diversificados materiais de estudo, as trocas e novas aprendizagens de técnicas de artesanato, de músicas, de danças, dentre outros elementos culturais. Neste sentido, a Pedagogia de Alternância é um instrumento importante na formação superior indígena.

São exemplos de ações no Tempo Universidade que contribuem para materializar esse princípio: aulas na Terra Indígena Rio das Cobras, inclusive com itinerância em diferentes aldeias; vivência do processo organizativo do curso na relação com a aldeia e sua organização social e política; gestão da alimentação e sobrevivência da turma; atividades de vivência com a escola básica-espaço das aulas; realização da itinerância entre tempo aula na aldeia e na universidade e demais Terras Indígenas; nas comunidades, a partir dos acadêmicos que frequentam o curso, demonstração, para os demais jovens, estudantes do ensino médio indígena das comunidades, que é possível acessar o Ensino Superior articulado às culturas, conhecimentos e línguas indígenas.

No Tempo Comunidade, são construídas ações que possibilitem vincular os acadêmicos aos processos educativos da Terra Indígena e aos processos escolares da educação básica indígena, por meio de intervenções com aplicação do que aprendem no Tempo Universidade e que fortaleçam o vínculo com a comunidade indígena.

\section{b) Alternância e os processos de auto-gestão no curso}

Historicamente, as relações que se constituem em espaços de educação formal são verticalizadas, cabendo aos estudantes uma participação restrita. Isso não é diferente no espaço da Universidade. Processos formativos com essa configuração de relações, pautadas em um modelo extremamente burocrático, potencializam uma formação para a submissão, para a eficiência produtiva, para a alienação.

No Curso de Pedagogia Indígena em questão optamos pautar as ações acadêmicas na ampliação da participação das lideranças e dos estudantes, especialmente por meio de processos de auto-gestão (UNICENTRO, 2018), passando esse a ser um dos princípios formativos a partir da Pedagogia da Alternância. Os estudantes são instados a se organizar em grupos de estudo e trabalho, ou seja, fazem a gestão coletiva do seu próprio processo formativo e de sua subsistência no curso, com tempos de estudo em aulas e com a realização de autosserviços (Shulguin, 2013) durante o TU e também no TC. 
Em diálogos coletivos foram criadas

várias equipes de trabalho compostas pelos

estudantes da turma, que permanecem

neles por uma das três etapas anuais do curso, podendo assim vivenciar processos de auto-organização em várias áreas. São

eles:

Quadro 2 - Equipes de trabalho e funções.

\begin{tabular}{|c|c|}
\hline $\begin{array}{l}\text { Equipe de } \\
\text { trabalho }\end{array}$ & Função \\
\hline $\begin{array}{l}\text { Disciplina e } \\
\text { Ética }\end{array}$ & $\begin{array}{l}\text { Possibilitar a vivência dos princípios de convivência no cumprimento de tempos e } \\
\text { horários, respeitando as decisões tomadas e a coerência com os princípios e valores da } \\
\text { Terra Indígena; garantir a segurança física e humana, conforme a orientação da } \\
\text { coordenação do curso e das lideranças locais; discutir e encaminhar para as instâncias } \\
\text { as situaçôes-problema que ocorram no curso. }\end{array}$ \\
\hline $\begin{array}{l}\text { Comunicação } \\
\text { Cultura e } \\
\text { Mística }\end{array}$ & $\begin{array}{l}\text { Organizar e coordenar a realização de atividades culturais durante o curso; assessorar } \\
\text { os Grupos de Trabalho nos seus momentos de místicas e em outros momentos; } \\
\text { organizar a ornamentação dos Espaços; ajudar a organizar os murais; pensar formas de } \\
\text { socializar as principais informações locais, nacionais e internacionais que envolvam os } \\
\text { sujeitos coletivos. }\end{array}$ \\
\hline $\begin{array}{l}\text { Saúde e bem } \\
\text { estar }\end{array}$ & $\begin{array}{l}\text { Organizar e coordenar a realização de atividades de descontração e concentração } \\
\text { durante as aulas; organizar ações de prevenção e acompanhar ações de promoção da } \\
\text { Saúde no curso; dialogar com o responsável pela saúde na aldeia quando alguma } \\
\text { situação precisar de encaminhamento médico. }\end{array}$ \\
\hline $\begin{array}{l}\text { Esporte } \\
\text { lazer }\end{array}$ & Organizar o cronograma de esportes da etapa, as caminhadas, promover exercícios. \\
\hline $\begin{array}{ll}\text { Relatoria } & \text { e } \\
\text { Memória }\end{array}$ & $\begin{array}{l}\text { Realizar o registro diário e a memória coletiva do curso; garantir o registro fotográfico; } \\
\text { socializar diariamente no tempo acolhida/interação o relato da memória do dia anterior. }\end{array}$ \\
\hline Infraestrutura & $\begin{array}{l}\text { Elaborar os cronogramas de limpeza e organização dos espaços coletivos, cronograma } \\
\text { da mística e manter diálogo com a coordenação do curso da escola e da aldeia } \\
\text { conforme as necessidades. }\end{array}$ \\
\hline $\begin{array}{l}\text { Ciranda } \\
\text { Infantil }\end{array}$ & $\begin{array}{l}\text { Organizar o espaço das crianças, acompanhar os educadores infantis, fazer o plano de } \\
\text { trabalho, avaliar o trabalho com os pais ou responsáveis (as crianças aqui indicadas, de } \\
\text { até } 4 \text { anos, vêm com as mães e ficam alojadas com o coletivo da turma, durante o TU). } \\
\text { A Ciranda é o espaço de cuidar e educar as crianças, o que tem sido feito por pais, a vós, } \\
\text { pessoas da comunidade e pelos próprios estudantes da turma em alguns momentos. }\end{array}$ \\
\hline
\end{tabular}

Fonte: UNICENTRO, 2018.

Esse processo gera uma coordenação

da turma, que representa o grupo nas instâncias de gestão do curso, de coordenação político-pedagógica e no colegiado. Isso efetiva outro princípio do curso, gestar a formação com protagonismo dos estudantes indígenas, suas culturas e histórias.

No Tempo Universidade realizamos várias ações para materializar esse princípio: gestão coletiva do curso com coordenação e lideranças dos estudantes; organização de grupos de trabalho (GTs), com lideranças em cada etapa, com escolha de nomes e palavras de ordem; realização de autosserviço (lavar louça, limpar espaços, preparar místicas, colher saladas, frutas e outros); momentos de avaliação nos GTs do processo formativo; realização de assembleias; vivências diárias de 
acolhida e místicas; escrita do diário e socialização na turma e outras, indicadas no quadro.

No Tempo Comunidade as ações, neste sentido, são: organização de grupos de estudo nas comunidades de origem; tempo pesquisa nas aldeias; reconhecimento dos espaços de gestão na aldeia e nas escolas; escrita individual do diário de campo, planejamento coletivo e intervenções nas comunidades, participando inclusive das ações indígenas de forma mais abrangente, como as recentes lutas pelo direito à saúde indígena.

Consideramos essa forma de organização elemento qualificador da Pedagogia de Alternância, pois potencializa uma formação omnilateral, possibilitando movimentar várias dimensões humanas: política, estética, cognitiva, afetiva, corporal, social, dentre outras. Também entendemos que se supera a gestão democrática meramente representativa, pois exige a participação de todos, assim, aproximando-nos das culturas e conhecimentos indígenas, objetiva-se formar sujeitos capazes de liderar e serem liderados, de planejar, de ter iniciativa, de se comprometer com projetos coletivos, que desenvolvem a empatia. Todas essas dimensões são importantes e potencializarão a atuação do pedagogo indígena na escola.

\section{c) Alternância como forma de valorizar a cultura indígena na formação}

Outro princípio fundamental na formação de pedagogos e pedagogas indígenas, assumido no curso e na sua alternância, é a cultura. Na raiz latina, a palavra cultura (colere) pode significar lavoura, cultivo agrícola, habitat. Segundo Williams (2011), ela vai assumindo sentidos ao longo da história, inclusive sentidos antagônicos. O que se toma aqui é sua raiz semântica original do termo em latim para significados diversos como habitar, cultivar, proteger, honrar com veneração, sugerindo, “... tanto regulação, como crescimento espontâneo. O cultural é o que podemos mudar ...”. (Williams, 2011, p. 13). Compreendendo a cultura e "o cultural" como princípio formativo, importa pensar o que podemos mudar, nos sujeitos, na formação, na educação e na escola. Quando decidimos o que queremos mudar e para que queremos transformar, precisamos também, reconhecer o que manter, fortalecer. Ambas dimensões em relação dialética, cultivar e/ou transformar.

Destacamos que esse processo de cultivar ou transformar cultura precisa ser um processo dialógico (Freire, 1987), e não de invasão cultural. Significa criar processos culturais em que todos se educam e, para esse momento, o todo é a 
universidade e seus formadores; as lideranças, os estudantes indígenas e seus contextos.

Para fazer a formação de pedagogos e pedagogas indígenas, a Universidade precisou transformar/manter sua cultura universitária: seus tempos (calendários, alternância, ritmos, mobilidade de professores); espaços (aula na aldeia, na universidade, nas demais terras indígenas); o currículo (com o ensino multilíngue); professores (engajados ou em engajamento, com pesquisas na área, de várias instituições, com presença de professores indígenas). Também os estudantes colocam-se em processos de manter e transformar a sua cultura, ou seja, combinar e cumprir os horários previstos; definir metas coletivamente e assumir sua execução; participar da gestão coletiva do curso; coordenar e ser coordenado nas instâncias (grupos de trabalho, lideranças, no trabalho); lavar louça e limpar espaços coletivos; poder fumar o cachimbo, fazer suas rezas, danças, pinturas, seus cantos; andar descalço, de cocar, pintado na universidade sem ser reprimido e discriminado; poder ouvir, falar, ler e escrever nas diferentes línguas (Guarani, Kaingang, Xetá, Portuguesa); escrever diariamente e ler textos científicos, poéticos, literários; expressar-se em público discutindo conceitos, debatendo ideias; aprendendo e ensinando.

Portanto, a formação superior indígena em curso, em uma proposta intercultural dialógica, precisa contribuir para o processo de transformação dos estudantes e da universidade, fato esse que faz com que comunidades indígenas busquem a universidade, demandem e façam parte da formação superior. Os povos indígenas não buscam nas universidades as suas culturas, pois elas não estão lá. Os Kaingang, Guarani e Xetá procuraram a universidade para ampliar, potencializar, fortalecer as suas culturas, colocá-las em pauta, em relação, para criar/ampliar o reconhecimento das suas próprias culturas de seus conhecimentos étnicos, articulando-os com os demais conhecimentos científicos entre sua juventude, dentre tantos outros aspectos.

As demandas por ensino superior que chegam às universidades no Paraná evidenciam que os povos indígenas querem a universidade e a formação. Os indígenas têm direito à universidade e a acessá-la de forma intercultural, a seu modo (Williams, 2008). Querem uma universidade com rostos indígenas, línguas indígenas, com produção científica indígena, saberes indígenas, intelectuais indígenas, com culturas indígenas. Querem para quê? Para fortalecer e educação indígena; forjar uma 
escola indígena com condução política e pedagógica dos seus profissionais; uma escola com rostos indígenas ensinando; com cantos, danças e línguas vivas e fortalecidas no currículo escolar indígena, não como algo a mais; uma escola contrahegemônica à escola capitalista, branca, colonizadora.

A relação entre o Tempo Universidade e o Tempo Comunidade, mediada pela alternância, situa a cultura e a torna processo vivo, pelo qual o conjunto de práticas e experiências indígenas, como os costumes, hábitos, trabalho, valores, crenças, comportamentos, convicções, saberes, artes, línguas, eivam entre si "todo um modo de vida" (Williams, 2008) e colaboram na formação dos pedagogos e pedagogas quando esses elaboram mediações entre a formação universitária, a vida e suas culturas. Sempre conflitantes e contraditórios, os elementos desse conjunto contam com uma base primária comum que permite distinguir modos de vida e culturas, entre si, que o autor compreende como "um modo total de vida", a cultura vinculada à produção "material e cultural" da existência. Logo, esses pedagogos e pedagogas, precisam ser impulsionados a construir essas relações, transformações e manutenções da cultura no processo de constituição da sua profissão a serviço das culturas indígenas, forjando, assim, experiências históricas dos intelectuais orgânicos indígenas (Williams, 2008), marcados pela experiência de classe e etnia.

Assim concebida, a cultura incorpora as questões e as contradições que a compõem e a constituem como um conceito (Williams, 2008), e será sempre formulada dentro de uma perspectiva que exige consciência histórica para ser analisada e compreendida, pois se realiza no movimento histórico. Dizia Williams, precisamos aprender e ensinar as conexões entre a formação política, econômica, cultural e educacional, para qualquer tipo de luta (Williams, 2007; 2008).

Para materializar este princípio, no Tempo Universidade realizamos ações que envolvem a criação de espaços da fala e da escuta das línguas indígenas; aulas de língua Guaraní, Kaigang, Xetá e Portuguesa; valorização da oralidade com tempo de ampliação vocabular na língua materna e portuguesa; vivência da dança, da pintura, da reza; uso da fogueira à noite; intercâmbio nas diferentes Terras Indígenas; exercício com jogos e brincadeiras indígenas; apresentação de conhecimentos científicos na língua portuguesa e o diálogo nas línguas maternas; conhecimento e experimentação de comidas tradicionais indígenas; presença dos rezadores e rezadoras 
(Txamõis, Txaryis, Kuiãs) para tratamento da saúde; exercícios de escritas em línguas indígenas com todas as suas diferentes grafias, em diferentes gêneros textuais; estudo da história dos povos indígenas; discussão de filmes/documentários sobre questões indígenas; inserção de professores e pedagogos indígenas na realização do Curso, sempre que possível; realização de oficinas de artesanato, escultura em madeira, cestarias e outras, visando potencializar o intercâmbio cultural.

No Tempo Comunidade, são exemplos de ações: pesquisa com sábios e sábias mais velhos quanto aos aspectos da cultura, conhecimentos e história; aplicação e pesquisa de jogos e brincadeiras com crianças e jovens; diálogos com os mais velhos e com as lideranças; registros e conhecimentos culturais da/na escola indígena local; intervenções em escolas indígenas com aplicação de conteúdos e metodologias de educação escolar indígena.

\section{d) Alternância e as lutas indígenas}

Nesta forma de construir um curso de Pedagogia - por meio da Pedagogia da Alternância - há um debate importante a ser enfrentado sobre o papel do pedagogo, assim como em outros processos. O pedagogo, tradicionalmente, recebeu como atribuição organizar

processos pedagógicos, produzir documentação escolar, coordenar a formulação de proposta político-pedagógica, assessorar docentes, atender aos responsáveis por estudantes, dentre outras. Em geral, suas atribuiçõos ficaram restritas aos espaços internos da escola. Nas perspectivas críticas de organização do trabalho pedagógico, a ação do pedagogo transcende os limites dos espaços escolares formais.

Se há uma ampliação da atuação do pedagogo, cria-se a necessidade de ampliar também os elementos da sua formação, que precisa, então, incluir vivências que contribuam para que ele construa/fortaleça o sentimento de pertença e de compromisso com a luta social, que exijam seu posicionamento diante das questões concretas da vida das comunidades, nas quais as escolas estão inseridas. Entendemos que formação política, consciência étnica, luta social e formação de pedagogo são questões indissociáveis.

No Tempo Universidade, temos nos preocupado com tais questões e articulamos algumas ações: participação em jornadas e eventos (exemplo recente foi a participação no III CIPIAL - Congresso Internacional dos Povos Indígenas, em Brasília); criação e coordenação de eventos; participação nas lutas concretas enquanto curso (um exemplo recente foi a 
participação da turma em manifestações dos docentes da Educação Básica em relação à Reforma da Previdência); liderança em negociações com governo e demais instituições para efetivar o curso e inseri-lo no financiamento do Ensino Superior no Paraná (exemplo recente foi a participação dos estudantes em reuniões junto à Secretaria de Estado da Educação e à Secretaria da Ciência, Tecnologia e Ensino Superior). No Tempo Comunidade, as atividades de intervenção propostas em cada etapa potencializam o envolvimento com as comunidades e, consequentemente, a participação nas lutas indígenas locais, estaduais e nacionais.

\section{e) Alternância, pesquisa no território indígena e a produção do conhecimento}

Por fim, não menos importante, outra relação possibilitada pela alternância na formação dos pedagogos e pedagogas é a pesquisa ou a leitura da realidade (Freire, 1987), no território pelos próprios sujeitos indígenas e a produção do conhecimento, a partir do olhar dos mesmos sobre seus contextos.

Freire (1987), na obra Pedagogia do Oprimido, traz contribuições fundamentais para pensar os processos de estudo da realidade, quando trata do oprimido e de sua condição de opressão, neste caso, os povos indígenas: "Quem melhor que os oprimidos, se encontrará preparado para entender o significado terrível de uma sociedade opressora? Quem, mais que eles, para ir compreendendo a necessidade da libertação?". (Freire 1987, p. 31). Portanto, o que eles têm a dizer, ler e escrever sobre seu território?

As questões postas colocam como desafio na formação a necessária capacidade dos formadores em ouvir os estudantes indígenas, indagar seu olhar sobre o contexto que exige a transição da consciência ingênua para a crítica transformadora. Não se reduz ao 'dar voz ao indígena', ele já tem voz, precisa 'ter a vez' de ler, dizer, questionar, sistematizar e produzir o conhecimento transformador. Confirma-se o que Freire (1984) denomina ato de ler, a ser compreendido enquanto um ato de intervenção no mundo.

Significa assumir processos de pesquisa com autonomia e autoria indígena, reconhecê-los e colaborar na condução dos mesmos a condição de intelectuais orgânicos de suas etnias. Neste sentido, trazemos ainda a contribuição de Caldart (2000) que, na obra Pedagogia do Movimento, dá um passo à frente quando diz que o Movimento educa, ou seja, as relações que os sujeitos (oprimidos) estabelecem em coletivo, um coletivo de classe e étnico, reeducam. Logo, o território indígena e seus coletivos de 
aldeia são o terreno fértil para produção da humanização e libertação da classe trabalhadora, nesse caso do povo indígena.

A pesquisa precisa ser processo e experiências étnicas dos povos indígenas, portanto, é necessário selecionar caminhos e perspectivas críticas para produção e organização do conhecimento. Destacamos algumas formas para ler a realidade: as caminhadas transversais, a metodologia das histórias de vida, história oral, a pesquisa sócio-antropológica, as etnografias, cartografias e o levantamento de temas culturais/geradores, o inventário da realidade, além de outros construídos junto com os sujeitos indígenas envolvidos neste processo formativo.

Para materializar esse princípio, no Tempo Universidade, realizamos e projetamos as seguintes ações: visitas e intercâmbios nas terras indígenas nas etapas do curso; produção da cartografia social dos estudantes e suas Terras Indígenas; produção das histórias de vida dos estudantes; registro das biografias dos Caciques; registro das narrativas indígenas; sistematização de material didático para as escolas indígenas; relação permanente entre os saberes indígenas e demais conhecimentos sistematizados ao longo da história; ações de itinerância do curso em diferentes Terras Indígenas; planejamento do trabalho docente a partir da realidade das comunidades indígenas de origem dos estudantes do curso.

No Tempo Comunidade as ações são: pesquisa engajada realizada nas aldeias, nas escolas e demais espaços educativos; recolha de dados para produção de cartografia social; realização do inventário da realidade; pesquisa do universo vocabular e os temas geradores para os processos de alfabetização; estágios do curso nas escolas e aldeias; realização de pesquisa e elaboração de projetos, relatórios, artigos, resumos.

As ações realizadas e projetadas demarcam um novo tipo de pesquisa - a engajada. Nesse sentido, a pesquisa não está distante da realidade, não tem fins meramente produtivos, é instrumento de desvelamento e compreensão do singular na relação com o particular e universal; promove a aproximação dos estudantes com as contradições da vida das comunidades, exigindo um posicionamento e consequentemente, potencializando o engajamento na luta social.

Esse conjunto de princípios que apontamos e as ações que realizamos e projetamos baseadas neles indicam claramente o quanto a Pedagogia da Alternância é instrumento para viabilizar o acesso e a permanência dos estudantes indígenas no Ensino Superior no Paraná, mas numa nova relação com a vida e com 
os conhecimentos, objetivando, assim, a formação de pedagogos que conhecem a realidade, que pesquisam, que debatem entre si, se posicionam, que se comprometem com a articulação universidade/comunidade e que se inserem nas lutas sociais. Além disso, a forma de organizar a alternância contribui para garantir a indissociabilidade entre ensino, pesquisa e extensão, entre teoria e prática.

Essa forma de organização do trabalho pedagógico realizado no Curso, com a efetiva participação dos povos indígenas, é uma iniciativa inédita no Paraná, porém apresenta, ainda, algumas dificuldades, tais como: precariedade de recursos financeiros para realizar as ações; dificuldade em inserir um número maior de professores indígenas como docentes do curso devido à falta de uma política de pós-graduação voltada aos povos indígenas no Paraná; pouca sensibilidade e envolvimento dos setores governamentais para compreender a importância dessa forma de organização que exige, além da contratação de professores e estrutura física, recursos para alimentação, hospedagem, transporte, contratação de equipe de acompanhamento das atividades realizadas no Tempo Universidade e no Tempo Comunidade.

\section{Considerações finais}

A formação do pedagogo tem feito parte de polêmicas complexas que envolvem a educação brasileira, mas, quando está relacionada às comunidades indígenas, novos elementos são explicitados, portanto velhas soluções já não resolvem mais as necessidades dos sujeitos que ali vivem. Há desafios a serem enfrentados em relação ao acesso e permanência de indígenas no Ensino Superior no Paraná, à forma de organização do trabalho pedagógico e do conteúdo dos processos de formação, aos objetivos que orientam tais processos, à permanência e conclusão dos cursos, dentre outros.

A Pedagogia da Alternância tem se apresentado como um instrumento inovador e importante para criar novas possibilidades de acesso e permanência, bem como para construir novas metodologias, para promover a inserção nas comunidades, para consolidar a formação política, para potencializar a participação e a valorização cultural.

Essa forma de organização de um Curso de Pedagogia específico para a formação de pedagogos indígenas traz desafios tanto para os professores como para os estudantes indígenas, pois colocam-nos a vivenciar situações de autoorganização, de convivência na diversidade étnico-cultural, de forma mais enfática na 
questão das línguas maternas indígenas, promovendo reflexões sobre o bilinguismo e sua efetiva presença tanto na Educação Básica como no Ensino Superior Indígena no Paraná.

O fortalecimento da coletividade, a partir dessas vivências, também coloca como desafio o engajamento dos professores e estudantes nas lutas indígenas, sejam elas relativas ao acesso a todos os níveis de ensino, ou relacionadas às questões da resistência, sustentabilidade e sobrevivência das comunidades indígenas.

A construção do Curso de Pedagogia Indígena, nessa forma de organização e com esses princípios, pretende contribuir para efetivar a participação indígena nos processos de formação superior no Paraná, promover novas formas de ensino e aprendizagem, explicitar as pedagogias indígenas, superar a situação precária e excludente dos Quadros Funcionais das escolas, nos quais há pouquíssimos pedagogos e professores indígenas, o que torna morosa a construção de escolas bilíngues interculturais, com currículos e projetos próprios feitos pelos profissionais indígenas junto as suas comunidades.

A realidade da educação escolar indígena no Paraná desafia as universidades a buscar novas formas de contribuir com a qualificação dos indígenas enquanto trabalhadores da educação, para que assumam tarefas de ensino, pesquisa, elaboração de materiais didáticos bilíngues, gestão, produção intelectual e acadêmico/cientifica, fortalecendo, ainda, a participação como lideranças, atuantes em todas as lutas indígenas pela consolidação e ampliação dos direitos indígenas.

Pretende-se, de forma participativa e intercultural, estimular a busca por novas epistemologias, considerando conhecimentos ancestrais indígenas, articulados com os demais conhecimentos científicos produzidos pela humanidade.

\section{Referências}

Almeida, W. B. (2004). Terras tradicionalmente ocupadas: processos de territorialização e movimentos sociais. Revista Brasileira de Estudos Urbanos e Regionais, 6(1), 9-32.

Barros, M. C. D. M. (1993). Linguística missionária: Summer Institute of Linguistics (Tese de Doutorado). Universidade Estadual de Campinas, São Paulo.

Bergamaschi, M. A., \& Silva, R. H. (2007). Educação escolar indígena no Brasil: da escola para índios às escolas indígenas. Ágora, 13(1), 124-150. Doi: http://dx.doi.org/10.17058/agora.v13i1.113 Recuperado em 07 de abril, 2019 de https://online.unisc.br/seer/index.php/agora larticle/view/113.

Betancourt, R. F. (1994). Questões de método para uma filosofia intercultural a 
partir da Ibero-América. São Leopoldo, RS: Editora Unisinos.

Brandão, C. R. (1988). Pesquisa Participante. São Paulo, SP: Editora Brasiliense.

Caldart, R. S. (2000). Pedagogia do Movimento Sem Terra. Petrópolis, RJ: Editora Vozes.

Caldart, R. S. (2017). Inventário da realidade: guia metodológico para uso nas escolas do campo. In Caldart, R. S. (Org.). Caminhos para a transformação da Escola 4 - Trabalho, agroecologia e estudo nas escolas do campo (pp. s./p.) São Paulo, SP: Editora Expressão Popular.

Carta-pedido de cursos superiores na Terra Indígena. (2018). Terra Indígena Rio das Cobras, Nova Laranjeiras, PR.

Censo Demográfico 2010. (2010). Rio de Janeiro, RJ: IBGE, Instituto Brasileiro de Geografia e Estatística. Recuperado em 10 de abril, 2019 de http://www.brasileirosnomundo.itamaraty. gov.br/a-comunidade/estimativaspopulacionais-dascomunidades/estimativas-do-ibge/censodemografico-ibge-2010.pdf

Constituição da República Federativa do Brasil de 1988. (2016). Texto constitucional promulgado em 5 de outubro de 1988, com as alterações determinadas pelas Emendas Constitucionais de Revisão nos 1 a 6/94, pelas Emendas Constitucionais nos 1/92 a 91/2016 e pelo Decreto Legislativo n. 186 (2008, julho 9). Brasília: Senado Federal, Coordenação de Edições Técnicas. Recuperado em 15 de junho, 2019 de https://www2.senado.leg.br/bdsf/bitstream/ handle/id/518231/CF88_Livro_EC91_201 $\underline{\text { 6.pdf }}$

Consulta Escola: dia a dia educação. (2018). Paraná. Secretaria de Estado da
Educação. Superintendência da Educação. Recuperado em 14 junho, 2018 http://www.consultaescolas.pr.gov.br/cons ultaescolas/f/inicial

Consulta sobre a possibilidade de oferta de curso de graduação para a formação de Educador Indígena na Terra Indígena Rio das Cobras. (2018). Paraná. Conselho Estadual de Educação. Parecer CEE/CP ${ }^{\circ}$ 03/18 de 19 de outubro.

Diretrizes Curriculares Nacionais para a Formação de Professores Indígenas no Ensino Superior. (2014). Brasília, DF: Ministério da Educação/Conselho Nacional de Educação.

Falkembach, E. M. F. (1995). Sistematização ... juntando cacos, construindo vitrais. Ijuí, RS: Editora Unijui.

Faustino, R. C. (2006). Política educacional nos anos de 1990: o multiculturalismo e a interculturalidade na educação escolar indígena (Tese de Doutorado). Universidade Federal de Santa Catarina, Florianópolis.

Faustino, R. C. (2012). Políticas educacionais e educação escolar indígena no Paraná. Universidade Federal de Santa Catarina: Recuperado em 13 de junho, 2019

de http://www.rizoma.ufsc.br/pdfs/936-of10b$\underline{\mathrm{st} 3}$

Faustino, R. C., Novak, M. S. J., \& Cipriano, S. C. (2013). A Presença indígena na Universidade: acesso e permanência de estudantes Kaingang e Guarani no ensino superior do Paraná. Revista Cocar, 7(13), 69-81.

Freire, P (1987). Pedagogia do Oprimido. São Paulo, SP: Editora Paz e Terra. 
Freire, P (2004). Ação cultural para liberdade e outros escritos. São Paulo, SP: Editora Paz e Terra.

Guimarães, E. (2005). Brasil: país multilíngue. Ciência e Cultura, 57(2), 2223.

Jara, O. (1985). Concepções dialéticas de educação popular. Caderno CEPIS. Texto de Apoio (2).

Junqueira, C. (2002). Antropologia Indígena: uma introdução. São Paulo, SP: Editora EDUC.

Lei $\mathrm{n}^{\circ} 6.001$ de 19 de dezembro de 1973. (1973, 21 de dezembro). Dispõe sobre o Estatuto do Índio. Diário Oficial da União, seção 1. Recuperado em 13 de junho, 2019 de

https://www2.camara.leg.br/legin/fed/lei/1 970-1979/lei-6001-19-dezembro-1973376325-publicacaooriginal-1-pl.html

Lei n. 9.394, de 20 de dezembro de 1996. (1996, 23 de dezembro). Estabelece as Diretrizes e Bases da Educação Nacional. Diário Oficial da União, seção 1.

Menezes, M. C. B. (2016) Educação escolar indígena e o processo de alfabetização enquanto apropriação da linguagem escrita (Tese de Doutorado). Universidade Estadual de Maringá, Paraná.

Novak, M. S. J. (2007). Política de ação afirmativa: a inserção dos indígenas nas universidades públicas paranaenses (Dissertação de Mestrado). Universidade Estadual de Maringá, Paraná.

Novak, M. S. J. (2014). Os organismos internacionais, a educação superior para indígenas nos anos de 1990 e a experiência do Paraná: estudo das ações da Universidade Estadual de Maringá (Tese de Doutorado). Universidade Estadual de Maringá, Paraná.
Ramos, A. R. (1984). O Brasil no movimento indígena americano. Anuário Antropológico, (82), 281-286.

Ramos, A. R. (2012). Constituições nacionais e povos indígenas. Belo Horizonte, MG: Editora UFMG.

Referencial Curricular Nacional para as Escolas Indígenas (1998). Brasília, DF: Ministério da Educação e do Desporto. Secretaria de Educação Fundamental MEC/SEF.

Rodrigues, I. C., \& Wawzyniak, J. V. (2006). Inclusão e Permanência de Estudantes Indígenas no Ensino Superior Público no Paraná: Reflexões. Recuperado em 18 de abril, 2019 de www.acoesafirmativas.ufscar.br/relatorio CUIA. 2006.

Sanches Vásquez, A. (1968). Filosofia da práxis. Rio de Janeiro, RJ: Editora Paz e Terra.

Shulgin, V. N. (2013). Rumo ao politecnismo: artigos e conferências. São Paulo, SP: Editora Expressão Popular.

Souza, H. J de. (2014). Como se faz análise de conjuntura. Petrópolis, RJ: Editora Vozes.

Teixeira, E. S., Bernartt, M. L., \& Trindade, G. A. (2008). Estudos sobre Pedagogia da Alternância no Brasil: revisão de literatura e perspectivas para a pesquisa. Educação e Pesquisa, 34(2), 227-242.

Doi:

http://dx.doi.org/10.1590/S1517-

$\underline{97022008000200002}$

UNICENTRO. Conselho de Ensino, Pesquisa e Extensão (CEPE). Resolução N ${ }^{\circ}$ 108-CEPE/Unicentro, de 23 de Setembro De 2008. Aprova o Regulamento do Programa Paranaense de Mobilidade 
Docente no Âmbito da Unicentro, PPMD/Unicentro.

UNICENTRO. (2018a). Laboratório da Educação do Campo e Indígena (LAECI). Departamento de Pedagogia (DEPED/G). Projeto Pedagógico do Curso de Pedagogia (Terra Indígena). Guarapuava, PR.

UNICENTRO. (2018b). Ofício n³29 GR/ UNICENTRO. 28 de setembro de 2018 b. Solicitação de autorização de funcionamento do Curso de graduação para a formação de Educador Indígena na Terra Indígena Rio das Cobras município de Nova Laranjeiras ao CEE.

Williams. R. (2007). Palavras-chave: um vocabulário de cultura e sociedade. Tradução de Sandra Guardani Vasconcelos. São Paulo: Editora Boitempo.

Williams. R. (2008). Cultura. Tradução de Lólio Lourenço de Oliveira. Rio de Janeiro: Editora Paz e Terra.

Williams, R. (2011). O campo e a cidade na história e na literatura. Tradução de Paulo Henrique Britto. São Paulo: Editora Companhia das Letras.

i Tratamos da formação continuada de professores
indígenas e não-indígenas das duas escolas Guarani
e das cinco escolas Kaigang, situadas no Município
de Nova Laranjeiras/PR e que configuram o
território denominado Rio das Cobras. (UNICENTRO, 2017).

ii O Programa Escola da Terra, edição 2018 - 2019, foi promovido e financiado pelo Ministério da Educação (MEC) e desenvolvido junto à Secretaria de Educação Continuada, Alfabetização e Diversidade (SECADI) e à Secretaria de Estado da Educação (SEED/PR), e foi executado pela UFFS na parceria com a UNICENTRO e a UFPR.

iii O Seminário reuniu aproximadamente 500 pessoas, em julho de 2018, para discutir e projetar o curso, entre elas, lideranças indígenas Guarani, Kaigang e Xetá, professores indígenas, gestores das escolas, Núcleos Regionais da Educação (NRE) e pesquisadores das IES do Paraná que fizeram, em parceria, os trabalhos.

${ }^{\text {iv }}$ Proporcionar o ensino intercultural e bilíngue por meio de estudos e conhecimentos científicos; contribuir para o fortalecimento e autonomia da organização social das comunidades indígenas e não indígenas; fomentar a história dos indígenas Kaingang, Guarani e Xetá, revitalizando aspectos linguísticos e socioculturais. (UNICENTRO, 2018).

Informações do artigo / Article Information

Recebido em : 02/08/2019

Aprovado em: 30/09/2019

Publicado em: 19/12/2019

Received on August 02nd, 2019

Accepted on September 30th, 2019

Published on December, 19th, 2019

Contribuições no artigo: Os autores foram os responsáveis por todas as etapas e resultados da pesquisa, a saber: elaboração, análise e interpretação dos dados; escrita e revisão do conteúdo do manuscrito e; aprovação da versão final publicada.

Author Contributions: The author were responsible for the designing, delineating, analyzing and interpreting the data, production of the manuscript, critical revision of the content and approval of the final version published.

Conflitos de interesse: Os autores declararam não haver nenhum conflito de interesse referente a este artigo.

Conflict of Interest: None reported.

Orcid

Marcos Gehrke

(iD) http://orcid.org/0000-0002-7592-3139

Marlene Lucia Siebert Sapelli

(iD) http://orcid.org/0000-0002-3682-8817

Rosangela Célia Faustino

(iD) http://orcid.org/0000-0002-0094-5528 
Gehrke, M., Sapelli, M. L. S., \& Faustino, R. C. (2019). A formação de pedagogos indígenas em alternância no Paraná: uma contribuição à interculturalidade e ao bilinguismo...

\section{Como citar este artigo / How to cite this article}

\section{APA}

Gehrke, M., Sapelli, M. L. S., \& Faustino, R. C. (2019). A formação de pedagogos indígenas em alternância no Paraná: uma contribuição à interculturalidade e ao bilinguismo. Rev. Bras. Educ. Camp., 4, e7350. DOI: http://dx.doi.org/10.20873/uft.rbec.e7350

ABNT

GEHRKE, M.; SAPELLI, M. L. S.; FAUSTINO, R. C. A formação de pedagogos indígenas em alternância no Paraná: uma contribuição à interculturalidade e ao bilinguismo. Rev. Bras. Educ. Camp., Tocantinópolis, v. 4 , e7350, 2019

http://dx.doi.org/10.20873/uft.rbec.e7350

DOI: 